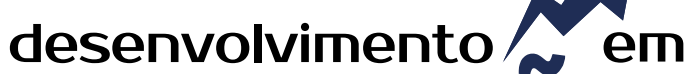 QUESTÂOO
}

\section{MODELO DE GESTÃO AMBIENTAL PARA UNIVERSIDADES COMUNITÁRIAS}

\author{
http://dx.doi.org/10.21527/2237-6453.2021.56.10699
}

Recebido em: $7 / 5 / 2020$

Aceito em: 5/5/2021

\section{Antônio Vanderlei dos Santos ${ }^{1}$, Ana Claudia Gierg Lourega², Emiterio da Rosa Neto²}

\begin{abstract}
RESUMO
A preocupação com questões ambientais e com o desenvolvimento sustentável está cada vez mais presente nas Instituições de Ensino Superior (IES). Assim, o objetivo geral desta pesquisa consiste em desenvolver um modelo de processo de gestão ambiental para universidades, tendo como base os dados obtidos na Universidade Regional Integrada do Alto Uruguai e das Missões - URI -, Campus Santo Ângelo, atendendo sua missão e valores, a fim de desenvolver a consciência coletiva e a sustentabilidade integrada com a conservação da biodiversidade. A metodologia utilizada foi a pesquisa-ação; um dos princípios fundamentais é a realização da pesquisa em ambientes onde acontecem as próprias práticas. Utilizou-se a estrutura da norma ISO 14001 como base de combater os impactos ambientais gerados para servir de exemplo no cumprimento da legislação, saindo do campo teórico para a prática. 0 trabalho caracteriza-se, também, como um estudo de caso. Utilizou-se a ferramenta PMBOK como base para construção de fluxo do processo. Destaca-se a importância de um SGA nas Instituição de Ensino Superior (IES) como forma de sensibilizar estudantes, professores e técnicos para o desenvolvimento sustentável. Alguns resultados mostram que é preciso que haja um processo de educação ambiental que seja efetivo, que realmente conscientize a comunidade universitária da necessidade de preservar o meio em que vive. As ações de sustentabilidade na universidade devem existir para produzir uma transformação institucional, uma mudança concreta na forma de agir e pensar de todos, tornando a preocupação ambiental cotidiana, comum, estando presente e influenciando desde as ações mais simples até as decisões estratégicas.
\end{abstract}

Palavras-chave: Instituições de Ensino Superior; sistema de gestão ambiental; desenvolvimento sustentável.

\section{MODEL FOR IMPLEMENTING AN ENVIRONMENTAL MANAGEMENT SYSTEM IN UNIVERSITIES}

\section{ABSTRACT}

The concern with environmental issues and sustainable development is increasingly present in Higher Education Institutions (HEls). Thus, the general objective of this research is to develop a model of environmental management process for universities, based on the data obtained at the Integrated Regional University of Alto Uruguai e das Missões - URI, Santo Ângelo campus, serving its mission and values, in order to develop collective consciousness and sustainability integrated with biodiversity conservation. The methodology used was action research; one of the fundamental principles is to conduct research in environments where the practices themselves take place. We use the structure of the ISO 14001 standard as a basis for combating the environmental impacts generated to serve as an example in complying with the legislation, leaving the theoretical field for practice. The work is also characterized by a case study. The PMBOK tool was used as a basis for constructing the process flow. The importance of an EMS in IES (Higher Education Institution) is highlighted as a way of sensitizing students, teachers and technicians to sustainable development. Some results are that there needs to be an environmental education process that is effective, that really makes the university community aware of the need to preserve the environment in which it lives. Sustainability actions at the university must exist to produce an institutional transformation, a concrete change in the way everyone acts and thinks, making everyday environmental concerns common, being present and influencing from the simplest actions to strategic decisions.

Keywords: Higher Education Institutions; environmental management system; sustainable development.

\footnotetext{
${ }^{1}$ Autor correspondente. Universidade Regional Integrada do Alto Uruguai e da Missões (URI). Rua Universidade das Missões, 464 - Bairro Universitário. Santo Ângelo/RS, Brasil. CEP 98802-470. http://lattes.cnpq.br/8299603681137935. https://orcid.org/00000002-6015-4218. vandao@san.uri.br

${ }^{2}$ Universidade Regional Integrada do Alto Uruguai e das Missões (URI). Santo Ângelo/RS, Brasil.
} 


\section{INTRODUÇÃO}

Há algum tempo, os responsáveis pela gestão de seus recursos econômicos, por suas propriedades e por tudo que resultar de suas ações, como os danos ao meio ambiente e a outros indivíduos, enfrentam dificuldades. No contexto empresarial, essa relação torna-se mais complexa devido ao aumento de recursos envolvidos, de resíduos gerados e da viabilidade econômica e operacional dos processos que abrangem a gestão ambiental - em artigo publicado em 2012 - os recursos tangíveis e intangíveis usados por uma organização para estabelecer estratégias voltadas à sustentabilidade e ao que essa gestão provoca no ambiente. $O$ trabalho foi desenvolvido na corporação Seara Marfrig, englobando a divisão aves e suínos do Grupo Marfrig Alimentos S.A., responsável pelo gerenciamento das marcas Seara, Mabella, Da Granja e Pena Branca, possuindo 30 unidades industriais localizadas em diversos Estados do Brasil (BRAZILIAN JOURNAL OF BUSINESS MANAGEMENT, 2012).

Logo, as questões ambientais passaram a ter impactos importantes sobre a competitividade dos países e de suas empresas (BARBIERI, 2004, p. 99-100), e a inserção da problemática ambiental, no panorama institucional, demanda um contínuo debate sobre a questão, o qual conduz a um certo consenso - entre a maioria dos países do globo - de que as medidas de proteção ambiental não foram criadas para impedir o desenvolvimento econômico. Essas medidas incorporam-se nas avaliações de custo/benefício ambiental, associadas ao desenvolvimento de projetos econômicos. Isso - por sua vez - leva à criação de novas regulamentações cada vez mais restritivas dentro de um contexto de execução de políticas governamentais; na Índia, existem estudos avançados sobre as ações governamentais interagindo com instituições (JAYARAM; AVITTATHUR, 2015).

No caso do foco do trabalho - atualmente - observa-se que as universidades têm voltado suas práticas e mobilizado seus esforços para contribuir com a preservação ambiental e a redução do impacto ambiental causado por suas atividades, buscando a harmonização da relação homem versus ambiente. Embora, no entanto, várias Instituição de Ensino Superior (IES) já manifestem preocupação e ações relacionadas com a gestão ambiental, poucas são as que possuem órgãos específicos destinados ao gerenciamento de suas questões ambientais (OLIVEIRA, 2002).

Para desenvolvimento de um sistema de gestão ambiental nas IESs, é preciso se adequar à legislação ambiental vigente, recorrendo à Constituição Federal Brasileira de 1988, que traz obrigações e definições ambientais nos artigos 20, 23 e 225, a Lei da Política Nacional do Meio Ambiente no 6.938/81 e a Lei de Crimes Ambientais no 9605/98 (BRASIL, 1988). Além das leis ambientais, torna-se necessário - também - compreender as normas de qualidade ambiental que servem como base para a introdução de Sistemas de Gestão Ambiental (SGA) pelas organizações, a exemplo das normas da família ISO 14000, dentre outras, e os acordos internacionais firmados (SEIFFERT, 2008).

A execução de um Sistema de Gestão Ambiental (SGA) nas universidades pode permitir que elas atinjam um nível de desempenho ambiental predeterminado e promovam sua melhoria contínua ao longo do tempo. Além de melhorar o desempenho, o sistema também melhora a imagem da universidade, que o utiliza perante o público, demonstrando à sociedade sua preocupação com o meio ambiente; no entanto ainda são poucas as práticas observadas nas Insti- 
tuições de Ensino Superior (IES), as quais têm o papel de qualificar e conscientizar os cidadãos formadores de opinião de amanhã.

Independentemente de serem instituições públicas ou privadas, as IESs devem cumprir seu papel em prol do desenvolvimento regional do local onde se inserem, promovendo a ética e a justiça, bem como o respeito e o atendimento às demandas sociais e ambientais (KRUGER et al., 2013). Desse modo, "o papel de destaque assumido pelas IES no processo de desenvolvimento tecnológico, na preparação de estudantes e fornecimento de informações e conhecimento, pode e deve ser utilizado também para construir o desenvolvimento de uma sociedade sustentável e justa" (TAUCHEN; BRANDLI, 2006, p. 503). Para que isso aconteça, torna-se indispensável que essas organizações comecem a incorporar os princípios e as práticas da sustentabilidade em todos os seus níveis para tomar decisões fundamentais sobre planejamento, treinamento, operações ou atividades comuns em suas áreas físicas.

De acordo com Araújo (2004), o papel da educação superior nas discussões sobre sustentabilidade vai além da relação ensino/aprendizagem vista em sala de aula. Assim, as universidades devem também servir como exemplo no gerenciamento dos seus resíduos, colocando em prática aquilo que ensinam, influenciando com resultados as organizações das quais os seus formados irão fazer parte, buscando a construção de um desenvolvimento social mais sustentável.

Cabe destaque para alguns estudos que abordam a gestão e a sustentabilidade e apresentam aproximação com este trabalho. O de Cintra (2011) investigou a introdução de um sistema de gestão ambiental e a melhoria do desempenho ambiental após a efetivação, além de avaliar a relação custo-benefício desta. A dissertação de Pires (2011) analisou as mudanças na gestão de pessoas de empresas que incluem a sustentabilidade em sua estratégia de atuação. $O$ trabaIho de Gonçalves (2014) - por sua vez - buscou compreender como ocorre a sustentabilidade integrada em uma organização empreendedora. Por fim, Galvão (2016) - em sua dissertação propôs um framework integrativo de inovação, sustentabilidade e gestão de projetos, adotando uma abordagem contingencial por tipo de projeto.

Dessa forma, nesta pesquisa, assim como em estudos prévios, procura-se evidenciar a importância da gestão ambiental nas organizações, buscando a efetivação de um modelo de processo de gestão ambiental numa instituição participante do Consórcio das Universidades Comunitárias Gaúchas (Comung), um sistema de educação superior existente no Rio Grande do Sul que reúne as instituições comunitárias de Ensino Superior do Estado, fundado em março de 1993 por nove universidades comunitários do RS.

O problema de pesquisa aqui desenvolvido é: Como um processo de gestão pode auxiliar na redução e eliminação dos impactos ambientais gerados? Assim, o objetivo geral da presente pesquisa é o de desenvolver um modelo de processo de gestão ambiental para universidades, tendo como base os dados obtidos em uma universidade no extremo sul do Brasil. O projeto de instalação de um processo de gestão ambiental em universidades utiliza a estrutura da norma ISO 14001 para efetivação do sistema na universidade, a qual deve combater os impactos ambientais gerados para servir de exemplo no cumprimento da legislação, saindo do campo teórico para a prática. A fim de alcançarmos a resposta e chegarmos ao objetivo do trabalho, usamos, como metodologia, a pesquisa-ação, conforme a que está fundamentada na realização da pesquisa em ambientes onde acontecem as próprias práticas. Nesta investigação realizamos um estudo de caso utilizando a ferramenta PMBOK como base para a construção de fluxo do processo. 
Este artigo apresenta os resultados da pesquisa da seguinte forma: iniciamos com a exposição do referencial teórico, em que descrevemos as principais referências usadas como base teórica; após, analisamos os resultados obtidos e realizamos algumas discussões. Por final, tecemos as considerações finais, quando ressaltamos as principais contribuições do artigo.

\section{REFERENCIAL TEÓRICO}

\section{Gestão Ambiental Empresarial}

Neste trabalho entendemos que a Gestão ambiental é um sistema de ações administrativas que enfatiza a sustentabilidade; logo, pode-se entender gestão ambiental como o uso de práticas e métodos administrativos que reduz - ao máximo - o impacto ambiental das atividades econômicas nos recursos da natureza, mas o conceito de gestão ambiental esta intimamente ligado a modelos de gestão social, descrito por alguns teóricos, como Junior (2020). A educação ambiental também tem uma importância vital na formação de conceitos de gestão ambiental, principalmente quando faz parte da formação do administrador que venha, por ventura, atuar na universidade (BARBIERI, 2016).

O que buscamos neste escrito é construir ações controladas num sistema de gestão para universidades comunitárias. Segundo Kraemer (2004), o desempenho ambiental satisfatório tem sido buscado por um número cada vez maior de empresas preocupadas com o gerenciamento dos assuntos pertinentes ao meio ambiente. Por meio de sistemas de gestão ambiental, as organizações empresariais investem em ações para um desenvolvimento sustentável em estudos sobre ciclo de vida dos produtos e sobre processos, geração, controle e tratamento de resíduos, consumo de recursos naturais e a questão do passivo ambiental.

Assim, para que uma empresa passe a realmente trabalhar com gestão ambiental, a mesma deve - inevitavelmente - passar por uma mudança em sua cultura empresarial, por uma revisão de seus paradigmas. Nesse sentido, a gestão ambiental tem se configurado como uma das mais importantes atividades relacionadas com qualquer empreendimento (KRAEMER, 2004). Segundo Barbieri (2004), entretanto, as preocupações ambientais das empresas não são espontâneas, senão influenciadas por três grandes conjuntos de forças que interagem: o governo, a sociedade e o mercado.

As propostas de gestão ambiental empresarial, alinhadas com as perspectivas ambientais, segundo Barbieri (2016), devem estar apoiadas a três critérios de desempenho que devem ser considerados simultaneamente, a saber: eficiência econômica, equidade social e respeito ao meio ambiente. Com a adoção destas propostas, espera-se que as empresas gerem renda e riqueza alinhadas com o cuidado com o meio ambiente, promovendo benefícios sociais e contribuindo para a construção de uma sociedade mais justa.

A adoção de qualquer modelo de gestão requer o uso de instrumentos, ferramentas e processos para alcance dos objetivos. Na gestão ambiental, auditorias ambientais, avaliação do ciclo de vida, estudos de impactos ambientais, relatórios ambientais, gerenciamento de riscos ambientais e educação ambiental, são apenas alguns entre vários instrumentos de que as empresas podem se valer para pôr em prática a gestão ambiental. 
À medida que a empresa busca desenvolver ações para o controle da poluição, caminhando para uma abordagem estratégica, maior será a variedade de instrumentos que ela poderá utilizar para atingir os objetivos a que se propôs alcançar (BARBIERI, 2016).

\section{Gestão Ambiental em IES}

As IESs têm um papel importante no desenvolvimento sustentável, afirmam Tauchen e Brandli (2006). Como instituições de ensino e pesquisa, essas ultrapassam o limite da preocupação em ensinar e formar alunos, ocupando papel importante no contexto da sociedade, com a responsabilidade social de capacitar pessoas conscientes da necessidade de garantir a sustentabilidade às gerações futuras.

Por sua vez, Kraemer (2004) salienta que as IESs assumem uma responsabilidade essencial na preparação das novas gerações, em busca de um futuro viável, pela reflexão e por seus trabalhos de pesquisa básica, concebendo soluções racionais e elaborando propostas coerentes para o futuro. Sendo assim, as IESs assumem um importante papel no que se refere ao desenvolvimento sustentável, abordando o tema sob a esfera educacional, formando profissionais e pesquisadores, e sob a esfera gerencial, criando SGAs em seus próprios campi universitários. Seguindo essa direção, Fouto (2002) - ao estudar o papel do Ensino Superior no desenvolvimento sustentável - apresenta a visão da Universidade Politécnica da Catalunha sob a forma de um modelo, conforme Figura 1.

Figura 1 - O papel da universidade na sociedade em relação ao desenvolvimento sustentável

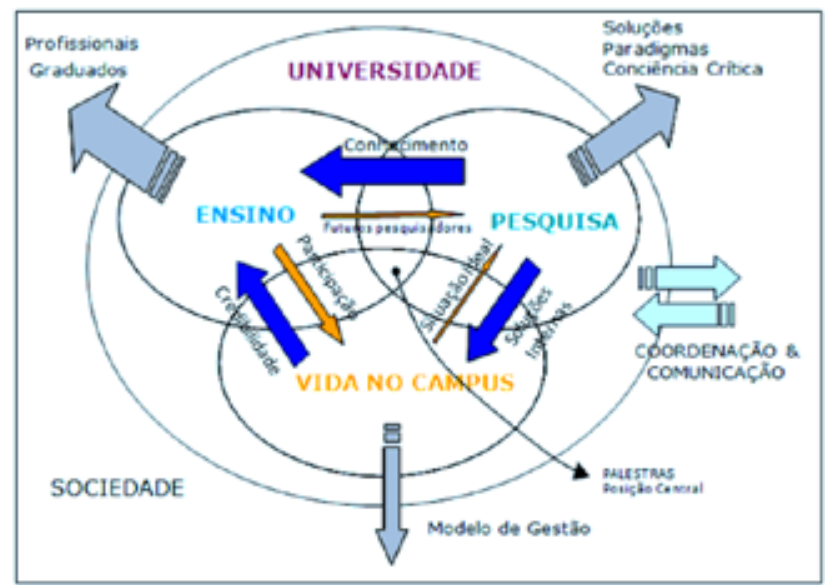

Fonte: FOUTO, 2002.

De fato, esse modelo pode ser generalizado e incorporado na visão comunitária de qualquer universidade, no Brasil e no mundo, pois adota um caráter de interação entre os diversos setores acadêmicos, entre si e - também - da IES como um todo, relacionando-se também com a comunidade externa (TAUCHEN; BRANDLI, 2006). Existem razões significativas para instalar um SGA numa Instituição de Ensino Superior e duas correntes de pensamentos principais que se destacam em relação ao papel das IESs no que se refere ao desenvolvimento sustentável. A primeira destaca a questão educacional, pois as IESs contribuem na qualificação de seus alunos, ofertando conhecimentos e práticas profissionais sustentáveis. A segunda corrente destaca a postura de algumas IESs na introdução de um SGA em seus campi universitários, servindo de exemplo de gestão sustentável para alunos e sociedade. 
Os benefícios do SGA, de acordo com Brandli e Tauchen (2006), vão desde economias pelo melhoramento da produtividade, redução no consumo de insumos básicos (energia, água e materiais de expediente) e atendimento das conformidades com a legislação ambiental, reduzindo possíveis penalidades ou geração de passivos ambientais, com a evidência de práticas responsáveis, melhora na imagem externa da instituição e geração de oportunidades de pesquisa.

No Brasil existem práticas sendo adotadas em várias IESs, destacando-se a Universidade Federal de Lavras (Ufla, MG), que foi eleita, em 2014, a Universidade mais Sustentável do Brasil e a 26a do mundo, segundo o ranking da UI Green Metric World University Ranking. O Plano compreende: um programa de gerenciamento de resíduos químicos focando ações preventivas de minimização (redução, reuso e reciclagem) e uma adequação do destino final dos resíduos oriundos das atividades de ensino, pesquisa e extensão, coleta seletiva, sistema de prevenção e controle de incêndios, proteção de nascentes e matas ciliares, saneamento básico e estação de tratamento de esgoto, construções ecologicamente corretas e sistema de prevenção de endemias (UFLA, 2014).

Outro exemplo que pode se citado é da IES Unisul (SC), e cada uma destas citadas busca atender áreas mais específicas, como utilização de energias renováveis.

A definição do modelo de gestão ambiental de um campus dependerá do levantamento dos requisitos legais e aspectos ambientais. Um dos métodos mais conhecidos para a criação destas metas e a geração de melhoria contínua dentro da indústria é o ciclo PDCA (plan - do check - act). Após a identificação desses, pode ser aplicado o PDCA para que sejam verificados aspectos ambientais da atividade exercida pela IES e a criação da política ambiental, avaliando e determinando os responsáveis e as ações de cada etapa do processo.

Uma vez elaborado um diagnóstico ambiental da instituição e sua(s) principal(is) demanda(s), será necessário desenvolver atividades de sensibilização com todos os envolvidos da IES (colaboradores e alunos), para que se possa chegar a um nível de qualidade na execução do SGA quando este for efetivado.

\section{Ferramenta (Project Management Body Of Knowledge) PMBOK}

No âmbito de projetos - na década de 60 do século 20 - duas instituições sem fins lucrativos foram criadas para padronizar o gerenciamento de projetos e avançar no estado da arte nessa área do conhecimento: o Institute for Project Management Association (Ipma) em 1965 na Europa, sendo a primeira organização internacional criada com esse foco, e o Project Management Institute (PMI), em 1969, nos Estados Unidos. O PMI promove atividades, eventos, estudos e treinamentos, além de bibliografias, dedicando-se ao avanço no gerenciamento de projetos, sendo o PMBOK sua publicação elaborada para padronizar e divulgar as boas práticas em gerenciamento de projetos.

Todo o gerenciamento de projetos possui a aplicação de conhecimentos, habilidades, ferramentas e técnicas às atividades do projeto, a fim de atender seus requisitos. São extremamente importantes à adaptação das diversas ferramentas as diferentes necessidades de cada projeto, adequando-se à complexidade de cada um. O PMBOK descreve 42 processos em cinco grupos (Iniciação - Planejamento - Execução - Monitoramento e Controle - Encerramento), dividindo tais processos em 9 áreas de conhecimento. 
Para falar sobre os conceitos e aplicações do sistema PMBOK, é necessário falar sobre conceitos e aplicações dentro de um gerenciamento de projetos, ou seja, o estudo que faz parte do conteúdo deste trabalho. $\mathrm{O}$ aumento da complexidade do desenvolvimento de produto depende de fatores que exercem influência sobre ele.

O desenvolvimento de produtos é - portanto - um dos mais importantes processos empresariais, pois dele depende a renovação do portfólio de produtos da empresa; por isso, sua longevidade no mercado (TOLEDO; JACOBI, 2013). Diariamente, projetos tendem a crescer em importância para as organizações; quanto mais essas estiverem alinhadas aos negócios das empresas, mais vantagens essas obterão na competição (KING, 1993).

\section{METODOLOGIA}

Por meio da metodologia são estabelecidos os procedimentos e recursos para que possa se realizar o fim da pesquisa, e para atingir os seus objetivos precisa-se saber qual o problema da pesquisa, ou seja, o caminho do projeto ao longo dela. Desse modo, "a especificação da metodologia da pesquisa é a que abrange maior número de itens, pois responde, a um só tempo, às questões: Como? Com quê? Onde? Quando?" (MARCONI; LAKATOS, 2010, p. 204).

A metodologia, então, tem o objetivo de explicar todo o conjunto de métodos utilizados para o desenvolvimento do trabalho; significa uma maneira de identificar como, onde e de que modo será realizada a pesquisa. Dessa forma, os próximos passos da metodologia são: descrição do método da pesquisa; apresentação da organização; coleta de dados; e análise e interpretação dos dados.

\section{A pesquisa}

Para melhor compreensão do processo de gestão ambiental, inicialmente foi realizada uma revisão bibliográfica utilizando a consulta de diversas fontes, como livros, artigos, monografias e, principalmente, a norma técnica da Associação Brasileira de Normas Técnicas da série NBR ISO 14001.

A prática deste trabalho foi realizada por meio de um estudo de caso in loco, com o Diagnóstico Ambiental da Universidade, incluindo o levantamento de toda a documentação e verificação do atendimento aos aspectos legais e a análise dos benefícios econômicos e estratégicos que o SGA trará para a Instituição. Esses procedimentos são realizados com recursos humanos internos, pois a Universidade já dispõe de pessoal habilitado ou relacionado com a gestão estratégica e as questões ambientais, permitindo a caracterização e a identificação dos principais aspectos e impactos gerados.

A responsabilidade de garantir que o processo do sistema de gestão ambiental siga seu fluxo baseado no PMBOK, também é da comissão, que realizará a análise dos aspectos ambientais da instituição, incluindo seus processos, produtos e serviços. Na fase de Introdução e Operação, são organizados os processos como forma de controlar e melhorar as atividades operacionais que são críticas do ponto de vista ambiental. Durante a Verificação e Ação Corretiva são contemplados monitoramento, medição e registro das características e atividades que podem ter um impacto significativo no ambiente. 


\section{Abordagem metodológica}

A metodologia utilizada na pesquisa foi a pesquisa-ação realizada no Campus da URI Santo Ângelo. Neste tipo de pesquisa, conforme Franco (2005, p. 489), um dos princípios fundamentais é "a realização da pesquisa em ambientes onde acontecem as próprias práticas". A pesquisa-ação requer um roteiro para direcionar sua execução.

[...] a pesquisa-ação é um tipo de pesquisa social com base empírica que é concebida e realizada em estreita associação com uma ação ou com a resolução de um problema coletivo e no qual os pesquisadores e os participantes representativos da situação ou do problema estão envolvidos de modo cooperativo ou participativo (THIOLLEN, 2011, p. 20).

Dessa forma, as práticas que contemplam esse trabalho foram efetuadas em conjunto com uma equipe envolvida com as questões ambientais da Universidade.

O trabalho caracteriza-se, também, como um estudo de caso. Segundo Bergamini (2005, p. 24), o estudo de caso permite uma melhor compreensão do estudo, pois desenvolve atividades de coleta, análise e apresentação de dados junto a um único local. Assim, o estudo de caso será realizado no Campus da URI - Santo Ângelo. Pretende-se utilizar a ferramenta PMBOK como base para a construção de fluxo do processo. A escolha do PMBOK deve-se ao fato de ele proporcionar o conjunto de ferramentas que permite que o processo seja executado de acordo com as necessidades da instituição.

Quanto à sua natureza, esta pesquisa pode ser classificada como pesquisa aplicada, pois caracteriza-se por seu interesse prático, e seus resultados serão aplicados na Universidade com a instalação de um processo de gestão ambiental. Quanto aos seus objetivos, a pesquisa pode ser classificada como descritiva, pois visa a descrever as características de um processo de gestão ambiental em Instituição de Ensino Superior envolvendo técnicas padronizadas de coleta de dados: questionário e observação sistemática.

A pesquisa pode ser classificada ainda como combinada, pois serão combinados aspectos das pesquisas qualitativas, quando o ambiente natural é a fonte direta para a coleta de dados e o pesquisador é o instrumento-chave, e quantitativas, porque a pesquisa requer o uso de recursos e de técnicas estatísticas (percentagem, média), que significa traduzir em números opiniões e informações para classificá-las e analisá-las em todas ou em algumas das etapas do processo de pesquisa.

Quanto aos métodos utilizados, a pesquisa envolve um estudo de caso e uma pesquisa-ação, pois é aplicado na URI e conta com uma equipe em busca da resolução de um problema coletivo.

\section{Coleta de dados}

A coleta de dados é o ato de pesquisar, juntar documentos e provas, procurar informações sobre um determinado tema ou conjunto de temas correlacionados e agrupá-las de forma a facilitar uma posterior análise. A coleta de dados permite que o pesquisador se situe diante da pesquisa, buscando soluções aos problemas detectados.

Nessa fase, durante o período de levantamento de informações da pesquisa, foram executadas diversas tarefas: 
- conhecimento das ferramentas de trabalho, PMBOOK, PDCA e ISO 14001, com estudo bibliográfico para conhecer e adaptar a aplicabilidade das ferramentas ao estudo proposto;

- levantamento de aspectos e impactos ambientais

- sistematização dos dados, organizando os dados encontrados após a etapa anterior, com a finalidade de subsidiar a construção do modelo de SGA.

- elaboração do modelo de SGA para o objeto de estudo; depois da etapa de sistematização, foi possível realizar a definição dos objetivos e metas do objeto de pesquisa, determinando as áreas ambientais gerenciáveis e a elaboração de práticas sustentáveis que colaboram para minimizar os impactos que o campus causa ao meio ambiente. Assim, a partir da obtenção desses dados, foi possível criar um modelo de SGA aplicável para o campus.

\section{ANÁLISE E DISCUSSÃO DOS RESULTADOS}

De acordo com as verificações feitas, o campus não possui um departamento responsável pelas questões ambientais. Encontramos apenas um servidor atuando como responsável pela coleta dos resíduos gerados, deixados em áreas específicas do campus pelos serviços de apoio (limpeza do campus) e pela garantia de sua destinação.

Observou-se, também, um comportamento ainda tímido das universidades nas questões de gestão ambiental, mas que já movimenta as ações para consolidação de tal gestão na IES. Embora ainda sejam raros os SGAs em instituições de ensino, alguns exemplos: a Universidade do Vale do Rio dos Sinos (Unisinos), que introduziu um Sistema de Gestão Ambiental por intermédio do projeto Verde Campus, sendo a primeira universidade da América Latina a ser certificada segundo a ISO 14001, como a Universidade Federal do Rio Grande do Sul (UFRGS); a Universidade Positivo (UP), que apresenta sucesso na execução dos mesmos, posto que a Unisinos e a UP possuem certificação segundo a ISO 14001. Estas conseguiram a certificação a partir do momento em que a alta direção se comprometeu com a gestão ambiental de forma a atender os requisitos da norma ISO 14001.

Uma das ações relevantes foi a criação do curso de Gestão Ambiental na Unisinos no ano de 2005, possibilitando a construção de laboratórios para estudo das questões ambientais, pesquisas e desenvolvimento de ferramentas de geoprocessamento e recursos para a formação de seus alunos (VERDE CAMPUS, 1997).

No momento não há nenhum estudo sobre os impactos ambientais gerados pela operacionalização da IES. Há, porém, ações para o descarte dos resíduos gerados pela Instituição, tendo maior atenção aos resíduos perigosos produzidos, principalmente, nos laboratórios de pesquisa, ensino e extensão. No processo de levantamento de dados foi verificado que há um plano de disposição e tratamento de resíduos com a descrição de normas para acondicionamento de resíduos e orientações com as normas e regras de como devem ser usados.

\section{Resíduos produzidos e necessidades de realocação}

Os tipos de resíduos gerados no campus são: orgânico, metal, papel, plástico, vidro; há, ainda, outros tipos específicos de resíduos oriundos, ou não, de laboratórios, tais como entuIho, papelão, madeira, lâmpadas fluorescentes, tintas, resinas, entre outros. Os resíduos la- 


\section{assemoummento QUESTÂO}

MODELO DE GESTÃO AMBIENTAL PARA UNIVERSIDADES COMUNITÁRIAS

Antônio Vanderlei dos Santos - Ana Claudia Gierg Lourega - Emiterio da Rosa Neto

boratoriais têm destino adequado dentro da própria instituição (segundo a Anvisa RDC-33, de 25/2/2003); os resíduos, como toner e cartucho de tinta, têm recolhimento específico. Não há cálculo de quantidade de cada tipo nem índice de geração per capita de resíduo que é gerado no campus atualmente.

As áreas comuns da universidade geram muitos resíduos, os quais se assemelham aos resíduos domiciliares, mas com porcentagem de recicláveis muito maior. Pode-se observar que os resíduos coletados são papéis diversos, embalagens de salgadinhos, copos plásticos e de isopor, garrafas pet de 2 litros e $600 \mathrm{ml}$, restos de comida (lanches das cantinas) e erva-mate. Percebe-se uma falta de educação ambiental e orientação por parte dos alunos, funcionários e servidores da universidade no que se refere à separação dos resíduos gerados. Pode-se notar que os lixeiros sempre apresentavam mistura de materiais, especialmente em sala de aula, contendo resíduos recicláveis e não recicláveis.

Ao final de cada turno os funcionários responsáveis pela limpeza recolhem os resíduos e os armazenam em um local específico sem a separação em recicláveis ou orgânicos. A Figura 2 apresenta a forma como - atualmente - os resíduos são dispostos e armazenados na instituição, até a empresa responsável fazer o recolhimento, transporte e concluir a destinação.

Figura 2 - Armazenamento de resíduos na instituição 1

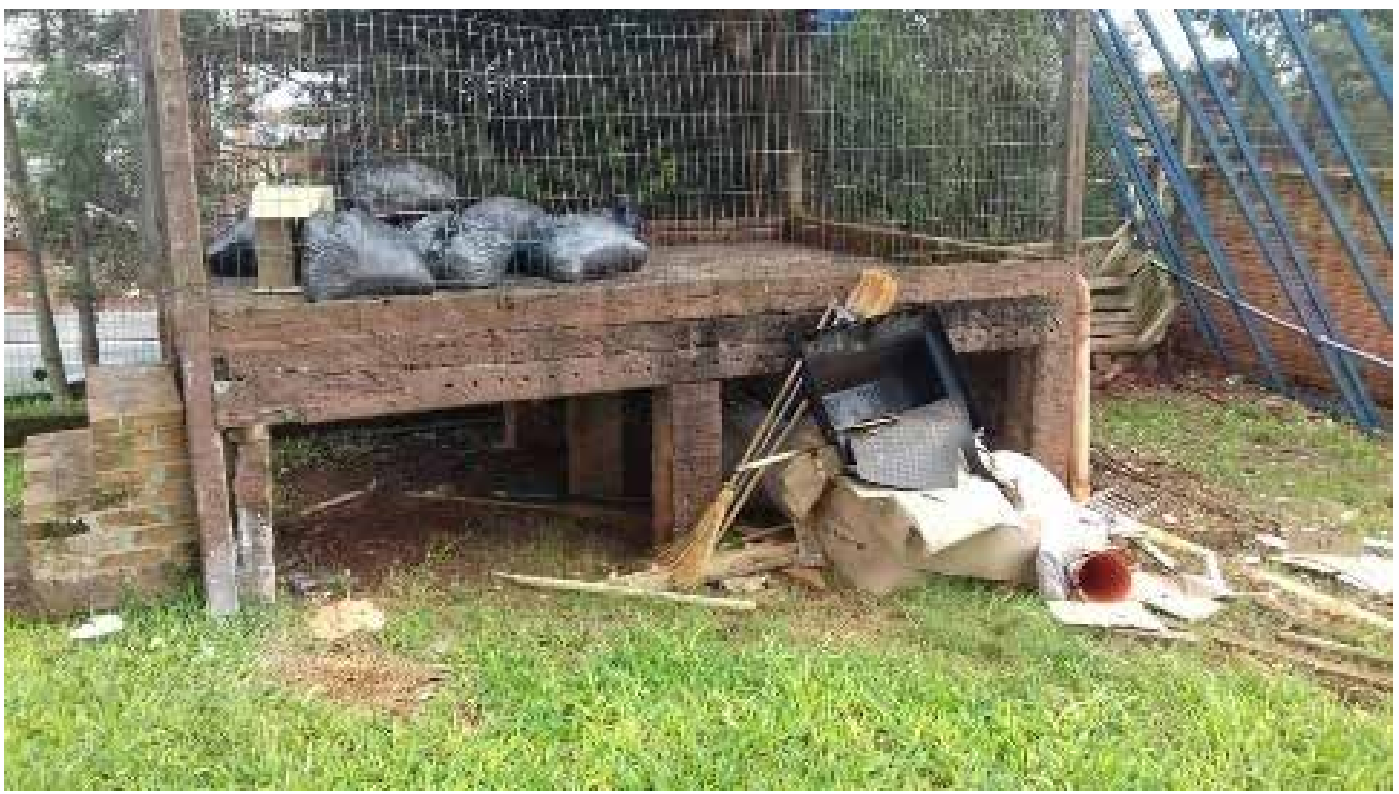

Fonte: Os autores.

Constatou-se que todos os resíduos sólidos recicláveis, atualmente produzidos no campus universitário, não possuem um local apropriado para o armazenamento até que seja realizada a coleta. De acordo com Tenório e Espinosa (2004), é fundamental que a coleta do lixo seja feita de forma separada, pois é isso que desencadeia o processo que permite maior agilidade na coleta, destinação correta, maior volume de reciclabilidade, menor volume de lixo destinado para aterros e preservação dos recursos e do meio ambiente.

Nas análises feitas nas salas de aulas e demais departamentos da IES, constatou-se que as lixeiras não possuem um padrão e nem identificação de tipos de lixo, o que acaba gerando uma mistura de todos os tipos de resíduos sólidos. 
Figura 3 - Lixeiras observadas na instituição
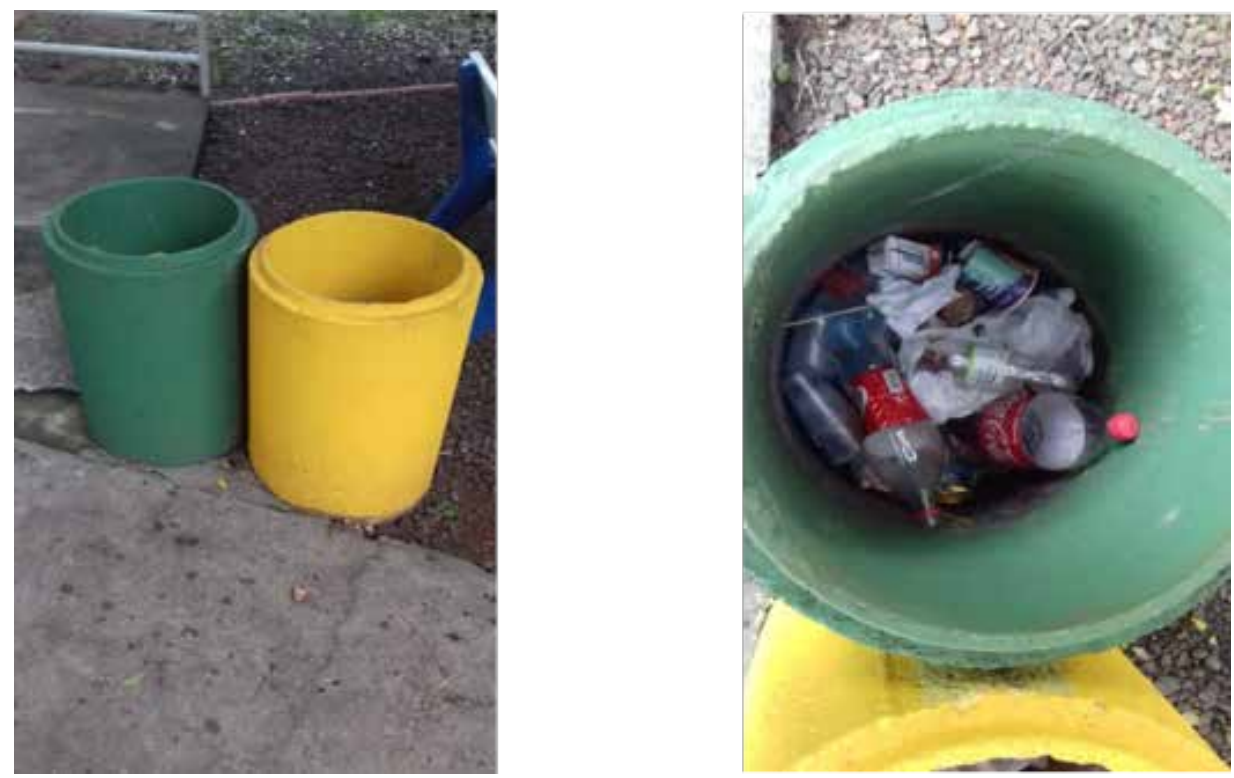

Fonte: Os autores.

Quanto ao gasto de água, foi possível levantar algumas informações. Atualmente toda a água utilizada pelo campus vem de poço artesiano; sendo assim, a instituição não tem despesas mensais com tratamento de água. Quanto ao seu resíduo, esse é disposto diretamente no esgoto, gerando uma importância significativa em seu impacto; com isso, é importante ressaltar que a IES pode desenvolver uma estrutura de reuso da água para outros fins, mitigando uma contrariedade da situação presente.

Durante a coleta de dados foi perceptível notar que alguns impactos ambientais são gerados por problemas de hábito de seus frequentadores; dentre eles, encontra-se o consumo excessivo de papéis, papel toalha, copos descartáveis e o hábito de deixar as lâmpadas, ares condicionados e/ou ventiladores ligados. Todos eles geram comprometimento dos recursos naturais, mostrando-se necessário o trabalho de conscientização e reeducação dos frequentadores.

Ainda, foi observado que o gasto de energia é consideravelmente alto para o porte do campus. Isso demonstra que a criação de um programa para incentivar alunos e servidores a economizar, visando a educação ambiental, se faz relevante. Existe, dentro da Instituição, um ponto de coleta de pilhas e baterias recolhidas por uma empresa do município que dá o destino adequado a elas no aterro industrial.

\section{Práticas a serem adotadas}

As universidades, para seu funcionamento, necessitam de uma infraestrutura básica, como redes de abastecimento de água e energia, redes de saneamento e coleta, vias de acesso, entre outras necessidades. Com isso, as IESs geram significativos impactos ambientais, com a manutenção constante dos edifícios e espaços, uso de produtos químicos em laboratórios, produção de resíduos perigosos, resíduos sólidos, consumo da água, energia, consumo de combustíveis, etc. 
A universidade traz, em seu histórico, algumas ações ambientais que - apesar de não serem formalizadas - podem contribuir com a adequação aos requisitos da Norma ISO 14001. Existem, porém, práticas para adoção de uma gestão ambiental no campus, dentre elas a construção de espaços para armazenamento de resíduos gerados na instituição, uma vez que os mesmos são dispostos em uma estrutura não muito apropriada para tal fim.

Um outro problema é a geração desordenada de resíduos e a sua separação incorreta, ou, muitas vezes, inexistente. Segundo a Resolução Conama no 275, de 25 de abril de 2001, Publicada no DOU no 117-E, de 19 de junho de 2001, Seção 1, página 80, o código de cores, para os diferentes tipos de resíduos deve ser adotado na identificação de coletores e transportadores bem como nas campanhas informativas para a coleta seletiva.

O Conselho Nacional do Meio Ambiente (Conama) é um órgão criado em 1982 pela Lei no 6.938/8, que estabelece a Política Nacional do Meio Ambiente. É o órgão consultivo e deliberativo do Sistema Nacional do Meio Ambiente - Sisnama - e existe para assessorar, estudar e propor ao governo as linhas de direção que devem tomar as políticas governamentais para a exploração e preservação do meio ambiente e dos recursos naturais. Além disso, também cabe ao órgão, dentro de sua competência, criar normas e determinar padrões compatíveis com o meio ambiente ecologicamente equilibrado e essencial à sadia qualidade de vida conforme o Decreto no 99.274, de 6 de junho de 1990 (BRASIL, 2019a).

O órgão recomenda a adoção de código de cores para programas de coleta seletiva estabelecidos pela iniciativa privada, cooperativas, escolas, igrejas, organizações não governamentais e demais entidades interessadas. Para essa não conformidade também há uma ação proposta que visa à conscientização e um possível treinamento com alunos, servidores e funcionários terceirizados. Além disso, faz-se necessária a construção de depósitos adequados para acondicionamento dos resíduos. Assim, pode-se atender ao Decreto Federal no 5.940/06, que dispõe sobre a separação correta dos resíduos recicláveis.

Figura 4 - Modelo de depósito de recicláveis - Unicamp

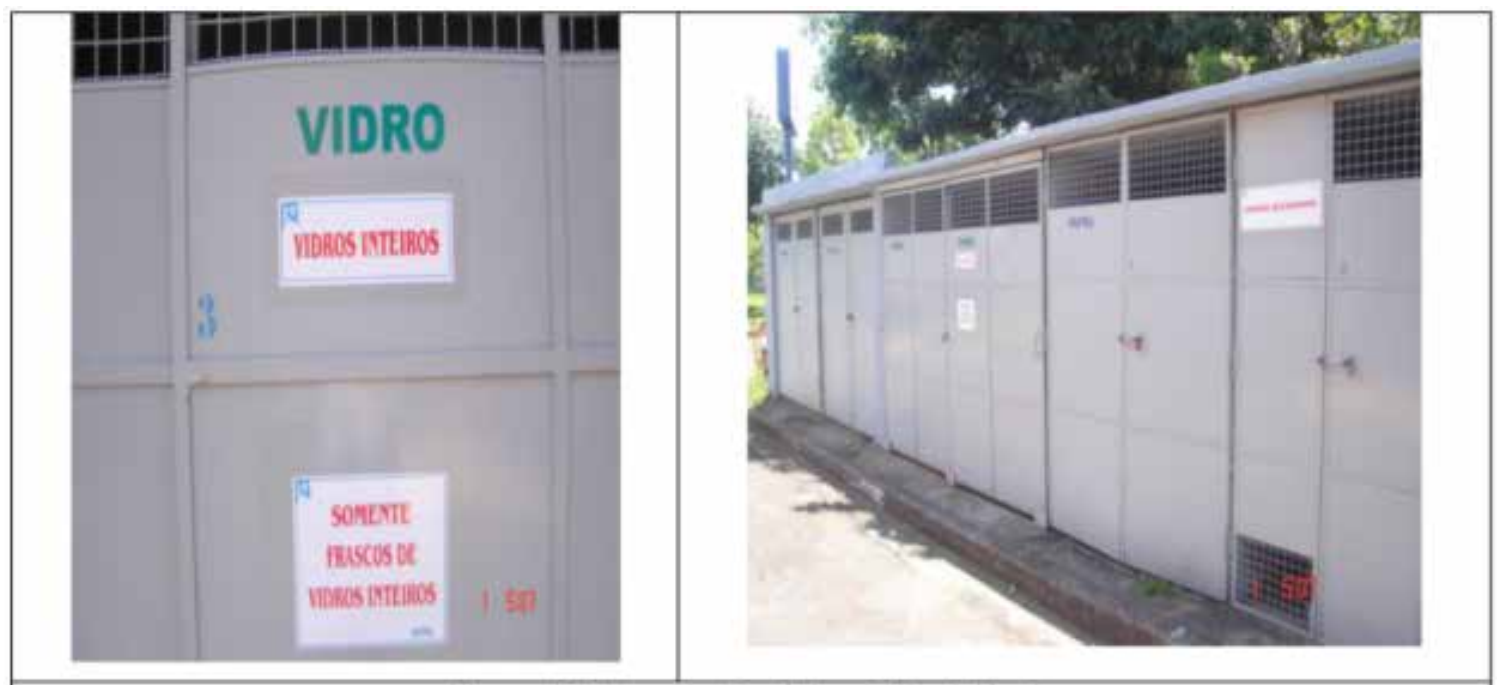

Fonte: UNICAMP (2020).

A área onde devem ser armazenados os resíduos: solventes (clorados, nitrogenados, sulfurados e não clorados), metais (forma sólida), resíduos sólidos orgânicos, lã de vidro, sílica e 
mercúrio, cádmio e chumbo (forma sólida) devem ter o completo atendimento das NBRs e deve estar embasado nas resoluções do Conama.

Figura 5 - Modelo de depósito de resíduos Unicamp

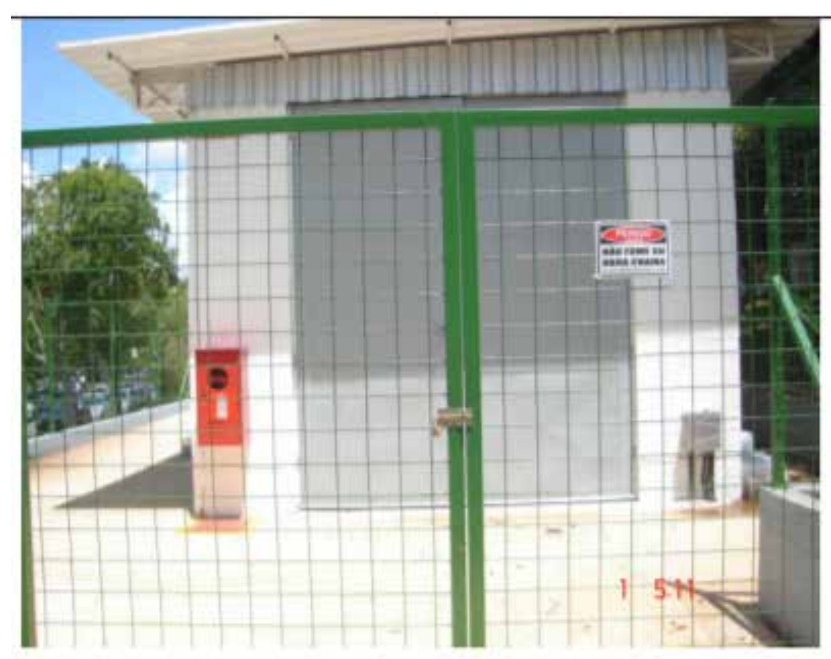

Fonte: UNICAMP (2020).

É possível o acondicionamento dos resíduos perigosos em tambores e contêineres, mas eles devem ser armazenados em locais com bacias de contenção. Isso é necessário para que, caso ocorra um vazamento, os líquidos derramados não penetrem no solo e em corpos d'água.

Os contêineres de resíduos perigosos sempre devem estar identificados; assim, evitam-se acidentes ou erros de classificação. O responsável sempre deve utilizar os EPIs adequados quando estiver manuseando resíduos perigosos e - ao final - deve ser dada a destinação correta ao equipamento utilizado.

É de responsabilidade do campus realizar a contratação de empresas que garantam o descarte adequado de cada componente utilizado. O Setor de Manutenção e Reformas entra em ação quando se trata da conservação de bens patrimoniais, transportando, acondicionando e destinando, de forma correta, materiais como gesso, caliça, madeira, até lâmpadas fluorescentes, por exemplo.

Quanto aos resíduos orgânicos do campus, o seu encaminhamento ideal é a compostagem. Não tendo acesso a uma composteira, o resíduo orgânico deve ser colocado em embalagens de papelão ou sacos de papel. Estes recipientes devem ser encaminhados para os depósitos de coleta. Em relação à redução de gastos com a energia, a IES pode buscar fontes alternativas de energia, como a solar, com células fotovoltaicas, eólica com instalação de turbinas e térmicas com aquecedores solares, e instalação de lâmpadas e sensores de presença; além disso, as campanhas educativas podem contribuir muito com a redução do consumo. Sobre o consumo de água, a primeira ação sugerida seria a eliminação de desperdício, identificando vazamentos e sanitários deficientes, com válvulas de descarga de menos consumo, realizando a captação da água da chuva e reuso da água utilizada, tratada na própria IES.

A questão da educação ambiental é tratada nos cursos de biologia e agronomia em alguns trabalhos de conclusão, com o viés da conservação da biodiversidade e o manejo de solo adequado. 
Para a introdução de um SGA no campus há muitos aspectos que precisam ser melhorados, iniciando pela realização de treinamento e capacitação dos servidores e funcionários terceirizados. É necessária a criação de programas que almejam capacitar e treinar os funcionários da melhor forma, para que a Política Ambiental seja seguida buscando sempre a melhoria contínua do SGA e, consequentemente, a redução do impacto ambiental.

\section{Construção do modelo}

Em todas as etapas de elaboração deste trabalho foi possível propor um processo de criação de um modelo de gestão ambiental para IES baseado no ciclo PDCA, utilizando o Guia do Conhecimento em Gerenciamento de Projetos - o PMBOK - e, obviamente, nas regulamentações de normas da ISO 14001. Segundo Barbieri (2004), o ciclo PDCA é uma forma de gestão que tem como objetivo a melhoria contínua com o alcance de metas traçadas e o planejamento das metas futuras.

O sistema PMBOK, utilizado neste trabalho, trata exclusivamente da execução e do gerenciamento do projeto para efetivação de um SGA em universidades, englobando todas as IESs. Com ele, espera-se a dinamização da própria instituição ao estabelecer um SGA, pois o PMBOK visa a proporcionar a integração de todos os setores envolvidos, possibilitando o acesso às informações sobre o andamento do projeto, além de dimensionar as etapas que necessitam de maiores atendimentos, assim como as dificuldades que cada setor terá no desenvolvimento das ações dentro desse projeto (PMBOK, guide (6th ed.)). Cada etapa, corresponde a uma fase do projeto, seguindo o padrão de gerenciamento exposto no guia PMBOK (2017), desde a fase inicial de pesquisa até seu encerramento (Anexo 1).

O ciclo PDCA deve ser posto em prática e seguido de acordo com suas especificações, prevendo os seguintes passos: política ambiental; planejamento; implementação e operacionalização; verificação e ação corretiva; e uma revisão permanente (PDCA) (TAUCHEN; BRANDLI, 2006).

Dessa forma, deve-se mapear o funcionamento organizacional da IES, sua estrutura física e organizacional, contratação de serviços e produtos e o impacto das atividades na comunidade e no ambiente. Nesse contexto, realiza-se um estudo sobre a legislação ambiental aplicável e o diagnóstico ambiental com aspectos e impactos ambientais, evidenciando o problema da geração de resíduos sólidos secos e úmidos, descarga de efluentes, do consumo de energia e a resistência humana ao novo modelo de gestão.

O planejamento deve observar toda a legislação de significativa importância no órgão estadual ou federal sobre licenças ambientais deste campus, e verificar se o mesmo foi ou não autuado por este órgão.

Resumindo, é na fase do planejamento que deve ser realizada toda uma análise dos aspectos ambientais da instituição, de seus processos, de seus produtos e serviços, assim como os bens e serviços usados pela organização. Em seguida, pode-se verificar quais são os pontos a serem melhorados no campus. Após os dados serem filtrados, pode-se realizar uma junção de informações para elaboração de um plano de ação (podendo utilizar a ferramenta 5W2H), definindo-se os objetivos e metas do SGA e buscando-se reduzir ou anular o impacto ambiental causado pelas atividades da IES. 
Quanto ao fator humano, devem-se efetuar medidas que visem à conscientização e educação ambiental dos frequentadores do campus, seja por meio de feiras, de palestras ou de cursos de reciclagem, capacitação e aperfeiçoamento profissional e desenvolvimento de atividades ambientais no campus (ESTEVES; HENKES, 2016; BOGDEZEVICIUS, 2017). A integração entre envolvidos e metas deve ser total; portanto, sem essa interação e o envolvimento de todas as áreas, o SGA não surtirá efeito prático.

O entendimento de todos os envolvidos no processo de gestão ambiental também se faz necessário nessa etapa, uma vez que a verificação deve ser feita por todos os níveis hierárquicos da gestão da IES, a fim de buscar as melhores medidas a serem tomadas. Na fase de verificação e ação corretiva, "a organização mede, monitora e avalia periodicamente o seu desempenho ambiental, realiza auditorias internas e uma avaliação do controle de registros" (NEVES; ROZEMBERG, 2010, p. 163).

Por fim, é necessário agir (action) no sentido de identificar os problemas e os novos desafios que surgiram durante a execução do SGA, quando novos planos de ação podem ser elaborados para alcance dos objetivos com medidas eficazes, aprimorando as anteriormente realizadas, corrigindo possíveis falhas no processo e reavaliando métodos (TORRES et al., 2018).

Nesta fase, a alta administração - juntamente com sua equipe - realiza auditorias do sistema de gestão ambiental. É importante que se faça uma avaliação do ciclo PDCA a fim de averiguar se ele está alcançando os objetivos e as metas traçados em períodos planejados, para garantir a sua adaptação e eficiência. Caso necessário, deve-se realizar melhorias e alterações na política, metas e objetivos ambientais (ABNT, 2004; NEVES; ROZEMBERG, 2010).

\section{CONCLUSÃO}

Apresentamos um modelo de gestão ambiental para as universidades que busca o desenvolvimento sustentável. Espera-se ter conseguido justificar que existem motivos claros para mudança de métodos de atuação e para investimentos das IESs neste sentido. Esses motivos reforçam a necessidade de diretrizes e modelos de atuação e práticas de sustentabilidade para execução de um SGA nas IESs.

A sociedade passou a se preocupar com questões ambientais recentemente, quando percebeu os prejuízos que poderiam decorrer do impacto ambiental ocasionado pelo mau uso do meio ambiente. Entre encontros e acordos internacionais, as legislações voltadas para a proteção ambiental foram evoluindo em vários países pelo mundo; no Brasil, não foi diferente.

A Constituição Federal de 1988 revelou a importância que a sociedade, o Estado e os instrumentos jurídicos devem ter quando se está diante de um bem jurídico ambiental. Consta na Constituição Federal do país a obrigação, por parte do Estado e da sociedade, de proteger o meio ambiente, considerando sua importância para a qualidade de vida humana e para a continuidade das atividades econômicas.

As Instituições de Ensino Superior (IES), por terem como objetivo principal produzir e difundir o conhecimento, também devem aplicar, em sua gestão, ações voltadas para a sustentabilidade, conforme previsão legal, além de colocar em prática aquilo que ensinam. Isso passa pela adoção da postura de exemplo e agente multiplicador de ações em prol da sustentabilida- 
de, promovendo a educação ambiental em todos os níveis de ensino, de maneira a desenvolver uma cultura voltada para a sustentabilidade na sociedade.

Neste trabalho, o estudo das políticas ambientais, a avaliação ambiental das IESs, a criação da política ambiental e a avaliação dos aspectos e impactos no estudo de caso, colaboraram para o desenvolvimento de uma proposta de instalação de um sistema de gestão ambiental. O processo de construção de uma comissão e o início do planejamento do sistema, todavia, dependem de inúmeros fatores. Mesmo que o modelo elaborado pareça ser bastante prático e aplicável, necessita sempre ser reavaliado buscando sua melhoria contínua.

É preciso que haja um processo de educação ambiental que seja efetivo, que realmente conscientize a comunidade universitária da necessidade de preservar o meio em que vive. As ações de sustentabilidade na universidade devem existir para produzir uma transformação institucional, uma mudança concreta na forma de agir e pensar de todos, tornando a preocupação ambiental cotidiana, comum, estando presente e influenciando desde as ações mais simples até as decisões estratégicas.

A principal meta do trabalho era criar um modelo de sistema de gestão ambiental para alcançar a sustentabilidade no Ensino Superior, pois uma IES é uma vivência da sociedade como um todo. Os campi são como as cidades e os alunos são os cidadãos sendo formados, sendo eles os futuros gestores que deixam os laboratórios e passam a praticar ações que combatam as práticas atuais não sustentáveis.

Por fim, afirma-se que será muito importante o envolvimento de toda a comunidade acadêmica - docentes, discentes e servidores técnico-administrativos - na execução das ações propostas no SGA, gerando oportunidades de pesquisa e extensão aos estudantes das IESs. Essas iniciativas acabam melhorando a imagem das IESs junto a comunidade externa, para que boas práticas sustentáveis sejam transformadoras e ultrapassem os limites dos campi, proporcionando mudanças de comportamento que resultem em atitudes sustentáveis e que tornem o nosso planeta melhor para a nossa e para as futuras gerações.

\section{REFERÊNCIAS}

ABNT. Associação Brasileira de Normas Técnicas. NBR ISO 14001. Sistemas de gestão ambiental - especificação e diretrizes para uso. Rio de Janeiro, 1997.

ABNT. Associação Brasileira de Normas Técnicas. NBR ISO 14001. Sistemas da gestão ambiental - Requisitos com orientações para uso. Rio de Janeiro, 2004. Disponível em: http://www.labogef.iesa.ufg.br/labogef/arquivos/downloads/nbr-iso-14001-2004_70357.pdf. Acesso em: 2 jun. 2019.

ABNT. Associação Brasileira de Normas Técnicas. Comitê Brasileiro de Gestão Ambiental (ABNT/CB-38). Disponível em: http://www.abnt.org.br/cb38. Acesso em: 18 maio 2019.

ANVISA. Resolução RDC n.o 33, de 25 de fevereiro de 2003. Dispõe sobre o Regulamento Técnico para o gerenciamento de resíduos de serviços de saúde. 2003. Disponível em: https://www.portaleducacao. com.br/conteudo/artigos/lideranca/resolucao-rdc-n-33-de-25-de-fevereiro-de-2003/6275.

ARAÚJO, M. I. O. A universidade e a formação de professores para a educação ambiental. Revista Brasileira de Educação Ambiental, Brasília, n. 0, p.71-78, nov. 2004.

BARBIERI, J. C.; SILVA. D. Educação ambiental na formação do administrador. 4. ed. São Paulo: [s.n.], 2020. BARBIERI, J. C. Gestão ambiental empresarial: conceitos, modelos e instrumentos. São Paulo: Saraiva, 2004.

BARBIERI, J. C. Gestão ambiental empresarial: conceitos, modelos e instrumentos. 4. ed. Fortaleza: Saraiva, 2016.

BERGAMINI, C. W.; CODA, R. Psicodinâmica da vida organizacional. 2. ed. São Paulo: Atlas, 2005. 
BRASIL. Ministério do Meio Ambiente. Agenda 21 Global. 1992. Disponível em: http://www.mma.gov.br/ responsabilidade-socioambiental/agenda-21/agenda-21-global. Acesso em: 5 ago. 2017.

BRASIL. Constituição Federal de 1988. Promulgada em 5 de outubro de 1988. Disponível em: http://www. planalto.gov.br/ccivil_03/constituicao/constituição.htm. Acesso em: 2 jun. 2019.

BRASIL. Política Nacional de Educação Ambiental - Lei no 9795/1999a, Art 1‥ Disponível em: www.mma. gov.br/port/conama/legiabre.cfm?codlegi=321. Acesso em: 2 jun. 2019.

BRASIL. Decreto no 99.274. Disponível em: www.planalto.gov.br/ccivil_03/decreto/Antigos/D99274.htm. Acesso em: 2 jun. 2019a.

BRASIL. Resolução Conama no 275. Disponível em: www.siam.mg.gov.br/sla/download.pdf?idNorma=291. Acesso em: 2 jun. 2019b.

BRASIL. Política Nacional de Educação Ambiental - Lei no 9795/1999b. Disponível em: www.siam.mg.gov. br/sla/download.pdf?idNorma=291. Acesso em: 2 jun. 2019.

BRASIL. Decreto no 5.940, de 25 de outubro de 2006. Institui a separação dos resíduos recicláveis descartados pelos órgãos e entidades da administração pública federal direta e indireta, na fonte geradora, e a sua destinação às associações e cooperativas dos catadores de materiais recicláveis, e dá outras providências. Disponível em: http://www.planalto.gov.br/ccivil_03/_ato2004-2006/2006/decreto/d5940.htm.

BRAZILIAN JOURNAL OF BUSINESS MANAGEMENT. Revista Brasileira de Gestão de Negócios, 23, p. 193, Apr./June 2012.

CINTRA, Y. C. A integração da sustentabilidade às práticas de controle gerencial das empresas no Brasil. 2011. Tese (Doutorado) - Universidade de São Paulo. São Paulo, SP, 2011.

ESTEVES, M.; G.; HENKES, J. A. Implementação de sistemas de gestão ambiental no meio empresarial: avaliação da utilização do ISO 14001 como ferramenta de melhoria de desempenho empresarial em indústrias no Estado de São Paulo. Revista Gestão \& Sustentabilidade Ambiental, Florianópolis, v. 5, n. 1, p. 453-472, abr./set. 2016. Disponível em: http://www.portaldeperiodicos.unisul.br/index.php/gestao_ambiental/article/view/3669/2632. Acesso em: 15 fev. 2018.

FOUTO, A. R. F. O papel das universidades rumo ao desenvolvimento sustentável: das relações internacionais às práticas locais. 2002. Dissertação0 (Mestrado em Gestão e Políticas Ambientais, Relações Internacionais do Ambiente) - Universidade Nova, Curso de Pós-Graduação em Administração, Lisboa, 2002.

FRANCO, M. A. S. Pedagogia da Pesquisa-Ação. Educação e Pesquisa. São Paulo, v. 31, n. 3, p. 483-502, set./dez. 2005.

GONÇALVES, Eder Borba. Sustentabilidade integrada em organizações empreendedoras: um estudo de caso. 2014. Dissertação (Mestrado) - Universidade Federal de Santa Catarina, Centro Tecnológico, Programa de Pós-Graduação em Engenharia e Gestão do Conhecimento, Florianópolis, 2014.

INTERNATIONAL ORGANIZATION FOR STANDARDIZATION. Environmental management - the ISO 14000 family of international standards. 2002. Disponível em: http://www.iso.ch. Acesso em: 2 jun. 2019.

JAYARAM, J.; AVITTATHUR, B. Green supply chains: a perspective from an emerging economy. International Journal of Production Economics, v. 164, p. 234-244, June 2015.

JUNIOR, A. V. Modelos e ferramentas de gestão. 4. ed. São Paulo: Senac, 2020.

KING, W. R. The Role of Projects in the Implementation of Business Strategy. In: CLELAND, D. I.; KING, W. R. Project Management Handbook. Nova York: Van Nostrand Reinhold, 1993.

KRAEMER, Maria E. P. Gestão ambiental: um enfoque no desenvolvimento sustentável. Biblioteca virtual da Unesp, 2004. Disponível em: wwwp.feb.unesp.br/renofio/.../GestaoAmbiental\%20Enfoquedes_sustentavel[1].doc. Acesso em: 10 ago. 2017.

KRAUS, Rosa R. Compartilhando o poder nas organizações. São Paulo: Nobel, 2005.

KRUGER, S. et al. Sustentabilidade ambiental: estudo em uma instituição de ensino catarinense. Sociedade, Contabilidade e Gestão, UFRJ, 8, p. 98-112, 2013.

LERIPIO, Alexandre de Avila. Gaia: um método de gerenciamento de aspectos e impactos ambientais. 2001. 172 p. Tese (Doutorado em Engenharia de Produção) - Universidade Federal de Santa Catarina, Programa de Pós-Graduação em Engenharia de Produção, 2001.

MARCONI, Marina de Andrade; LAKATOS, Eva Maria. Fundamentos de metodologia científica. 7. ed. São Paulo: Atlas, 2010.

NEVES, E. B.; ROZEMBERG, B. Estudo comparativo entre o sistema de gestão ambiental do exército brasileiro e a norma ISO 14001. Revista de Gestão Social e Ambiental, São Paulo: RGSA, v. 4, n. 1, p. 159-177, 2010. 
ONU. Programa das Nações Unidas para o Meio Ambiente - PNUMA. Disponível em: https://nacoesunidas.org/agencia/onumeioambiente/. Acesso em: 2 jun. 2019.

PIRES, Fernanda Mendes. Integração entre gestão de pessoas e estratégia de sustentabilidade: evidências em organizações contemporâneas. 2012. Dissertação (Mestrado em Administração) - Faculdade de Economia, Administração e Contabilidade, University of São Paulo, São Paulo, 2012. DOI:10.11606/D.12.2012. tde-26032012-211511. Acesso em: 2021-10-18.

PMI. Project Management Institute. Um guia do conhecimento em gerenciamento de projetos (Guia PMBOK). 4. ed. Atlanta: Global Standard, 2008.

SEIFFERT, M. E. B. ISO 14001: Sistemas de gestão ambiental: implantação objetiva e econômica. 3. ed. São Paulo: Atlas, 2008.

TAUCHEN, J.; BRANDLI, L. L. A gestão ambiental em instituições de Ensino Superior: modelo para implantação em campus universitário. Gestão \& Produção, v. 13, n. 3, p. 503-515, set./dez. 2006.

TENÓRIO, J. A. S., ESPINOSA, D. C. R. Curso de Gestão ambiental. Barueri: Manole, 2004.

THIOLLENT, Michel. Metodologia da pesquisa-ação. 18. ed. São Paulo: Cortez, 2011.

TOLEDO, R. F.; JACOBI, P. R. Pesquisa-ação e educação: compartilhando princípios na construção de conhecimentos e no fortalecimento comunitário para o enfrentamento de problemas. Educ. Soc., Campinas, v. 34, n. 122, p. 155-173, jan./mar. 2013.

TORRES, T. L. et al. Gestão do uso da água na indústria: aplicação do reuso e recuperação. Revista Gestão \& Sustentabilidade Ambiental, Florianópolis, v. 7, n. 2, p. 370-385, abr./jun. 2018. Disponível em: http:// www.portaldeperiodicos.unisul.br/index.php/gestao_ambiental/article/view/6216/3762. Acesso em: 28 abr. 2018.

UFLA. Universidade Federal de Lavras; MEC. Ministério da Educação. Coletânea desafio da sustentabilidade. 2014. Disponível em: http://desafiodasustentabilidade.mec.gov.br/coletanea.pdf. Acesso em: 25 abr. 2017.

UNICAMP. Universidade Estadual de Campinas. Plano de Gerenciamento de Resíduos (PGR) do Instituto de Química. 2020. Disponível em: https://iqm.unicamp.br/sites/default/files/Plano\%20de\%20Gerenciamento\%20de\%20res\%C3\%ADduos.pdf.

UNISUL, Universidade do Sul de Santa Catarina. Projeto de Eficiência Energética da Celesc. Disponível em: http://hoje.unisul.br/grupo-de-pesquisa-inaugura-projeto-de-eficiencia-energetica-na-unisul/. Acesso em: 14 abril 2017.

UNISUL. Universidade do Sul de Santa Catarina. Unisul Solar. Disponível em: http://hoje.unisul.br/unisul-solar-e-inaugurada-no-campus-de-florianopolis/. Acesso em: 20 abr. 2017.

UPF. Universidade de Passo Fundo. Disponível em: http://www.upf.br/. Acesso em: 14 abr. 2017.

VARGAS, Ricardo. Plano de gerenciamento, utilizando o PMBOK. 3. ed. Rio de Janeiro: Editora Brasport, 2007.

VERDE CAMPUS. Unisinos. 1997. Disponível em: http://www.unisinos.br/verdecampus/. Acesso em: 12 maio 2019. 